\title{
Assessment of accuracy of mercury sphygmomanometer and automated oscillometric device of blood pressure measurement in population of normal individuals
}

\author{
Ravindra Wadhwani', Nazeem I Siddiqui' ${ }^{2}$, Balkishan Sharma ${ }^{3}$ \\ ${ }^{1}$ Associate Professor, Department of Physiology, M. G. M. Medical College Indore, (Madhya Pradesh) India, ${ }^{2}$ Professor \\ and HOD, Department of Physiology, Government Autonoumous Medical College Khandwa, (Madhya Pradesh) \\ India, ${ }^{3}$ Associate Professor (Biostatistics), Department of Community Medicine, Sri Aurobindo Medical College and \\ P. G. Institute, Indore (M. P.), India
}

Background: Blood pressure (BP) measurement is the most common investigation performed nearly on all patients' for diagnosis and treatment of hypertension. Accuracy of the measurement device is crucial for timely diagnosis. However, sphygmomanometer requires medical expertise whereas automated oscillometric device needs only careful observations in measuring BP. Aims and Objectives: The objective of the present study is to determinethe comparative accuracy of mercury sphygmomanometer and automated oscillometric device of measuring BP and the limit of agreement between the two devices. Materials and Methods: A cross-sectional study designed and carried out at MGM Medical College, Indore among 438 normal individuals. Age, weight, height, body mass index, history and BP were recorded. An average of three recording of BP measurement by both the devices was used. Results: Out of a total, $52.3 \%$ were male and $47.7 \%$ were female. Average SBP $(130.78 \pm 17.31 \mathrm{mmHg})$ and DBP $(86.96 \pm 10.26 \mathrm{mmHg})$ measured by automated instrument were significantly elevated than SBP $(126.32 \pm 13.47 \mathrm{mmHg})$ and DBP $(81.70 \pm 8.63 \mathrm{mmHg})$ by mercury sphygmomanometer while the mean differences in SBP and DBP $(5.16 \pm 4.40$ and $5.57 \pm 3.30 \mathrm{mmHg})$ were statistically significant $(p=0.000)$. Hypertension reported in more patients with automated $(79.0 \%)$ compared to sphygmomanometer $(76.0 \%)$. Bland-Altman plots indicated a positive linear trend for $\mathrm{BP}$ readings between two instruments. Differences were more in SBP reading than DBP within three categories. Measurement of agreement indicated strong statistically significant $(p=0.000)$ mutual agreement between the rate of judging hypertension by two apparatuses. The coefficient of determination for SBP $\left(R^{2}=0.95\right)$ and $D B P\left(R^{2}=0.87\right)$ were very high when manual readings compared to automated. Conclusion: Present research suggests that BP readings obtained by automated and sphygmomanometer is comparable however as compared to mercury sphygmomanometer ocillometric device gives slightly higher readings of SBP. Looking towards the simplicity of measurement and freedom from environmental toxicity automated ocillometricdevice may be recommended as a primary tool for early detection and management of high BP.

Key words: Blood pressure measurement; Sphygmomanometer; Hypertension; Automated Oscillometric device; Systolic blood pressure; Diastolic blood pressure 


\section{INTRODUCTION}

Early diagnosis of hypertension is essential for timely management and prevention of its complication. Accuracy of the BP measurement plays a crucial role in curbing the menace of hypertension and to decrease associated morbidity which a matter of great public health concern. ${ }^{1}$ High blood pressure is ranked as the third most important risk factor of attributable burden of disease in south Asia (2010) and the prevalence for hypertension in India was $29.8 \%{ }^{2}$ and, is directly responsible for $57 \%$ of all stroke deaths and $24 \%$ of all coronary heart disease deaths. ${ }^{3}$

Therefore, to reduce burden of deaths from coronary heart diseases and other diseases timely diagnosis of hypertension is must which is dependent onaccuracy of the BP measurement device. Falsely underestimated or overestimated readings both put the patient to risk. An underestimated reading, the patient is at a risk of hypertension related diseases, which can significantly reduce life expectancy whereas an over estimated reading exposes the patient to the hazards of treatment of hypertension. Therefore an accurate reading is essential. ${ }^{4}$ There are different invasive and non-invasive methods available to measure blood pressure. ${ }^{5}$ The blood pressure should be measured in both the arms because differences exist and measurement in only one arm may lead to under diagnosis of hypertension. ${ }^{6,7}$ However, the inter-arm blood pressure difference is efficient diagnostic tool for diagnosis of hypertension and disorders related to hypertension. ${ }^{8}$

There are three non-invasive modalities commonly used to check BP throughout the world such as manual mercury sphygmomanometer, aneroid meter and the automated oscillometric device (digital). The manual mercury sphygmomanometer is considered to be the gold standard. ${ }^{9}$ Mercury sphygmomanometers had been used by healthcare professionals over the last 100 years in both hospital and ambulatory settings as a gold standard. ${ }^{10}$ But, there is no long-term future for these mercury based devices ${ }^{11}$ due to potential environmental toxic effects of mercury $(\mathrm{Hg})$. These devices banned in European countries such as Sweden and Netherlands as well as in the United States. ${ }^{12-13}$

An approach is necessary to identify the alternative device which is easier and competent in measuring BP. Nonmercury sphygmomanometers like aneroid and more recently, digital ones have replaced the use of traditional mercury instruments in many settings. This device translates arterial pressure into oscillometric wave and with system built algorithm display readings. ${ }^{10}$

Oscillometric devices are gaining fame since these devices are considered environmentally safe and have a significant advantage over their manual counterparts (mercury or aneroid) and they don't require a trained professional to measure BP. Among the various advantages of the available replacements of mercury devices, aneroid instrument has the portability ${ }^{14}$, while that of digital instruments are ease of use and they obviates the need of auscultation skill of the examiner. ${ }^{15}$ Thus these devices are recommended and used in various population surveys of $\mathrm{BP}$ recording. ${ }^{16}$ Moreover they are also useful for ambulatory BP recordingsand for monitoring blood pressure at home, ${ }^{17}$ to add further they are free from the bias of white coat hypertension thus give more accurate readings. ${ }^{18,19}$

Keeping the above in mind the present study was performed to identify the accuracy of automated oscillometric (digital) measuring devices of measuring blood pressure ascompared to mercury sphygmomanometer (manual)and the limit of agreement between the two devices.

\section{Objective of the study}

The present study aims to compare the accuracy of BP measurement by mercury sphygmomanometer and automated oscillometric measuring device and to find out limits of agreement between the two devices. The findings of the study were analyzed and discussed.

\section{MATERIALS AND METHODS}

\section{Background and study design}

A cross sectional study designed and carried out at Mahatma Gandhi Memorial Medical College, Indore (M. P.), India among normal healthy individuals.

\section{Participants and data collection method}

Out of a total of 612 ,four hundred thirty eight $(\mathrm{N}=438)$ normal individuals selected randomly for the study. Ethical approval and prior informed consent fromthe subjects were obtained. Individuals aged between 20 and 84 years of both the sexes but without diseases were participated in the study. Age in completed years, sex, weight by digital weighing scale with accuracy of 50 grams, height in centimeter by stadiometer, body mass index (BMI), and blood pressure by two devices were recorded using standard protocol. An average of three recordings of blood pressure measurement by both the devices was used for analysis.

\section{Blood pressure measurements}

All normal individuals who were the attendees of patients were assessed by one trained doctor experienced in collecting clinical data. Following 5 minutes of rest in supine position, both palpatory and auscultatory methods were used to record the BP using validated standard sphygmomanometer and automated oscillometric measuring device with appropriately sized cuffs in right 
arm. Three readings for systolic blood pressure (SBP) and diastolic blood pressure (DBP) were noted for specified arm and the average of BPs was used for further analysis. All the measurements were taken between 10:00 AM to 1:00 PM.

\section{Statistical analysis}

The data analyzed by using SPSS 17.0 trial version. Descriptive and inferential statistics were used. Results for continuous variables presented as mean \pm standard deviation while categorical as numbers (\%). This was assumed that the observations recorded for a continuous variable had followed a normal distribution.Z-test and one way analysis of variance used to compare the mean values of BP recordings. Cohen's kappa statistic used to measure the agreement between two measuring devices.

Regression analysis was also computed to project the relationship between the automated oscillometric and manual blood pressure readings. The probability value $\mathrm{p} \leq 0.05$ was considered as significant while $\mathrm{p} \leq 0.01$ and above were considered as highly/strongly significant.

\section{RESULTS}

Out of a total of 438 normal individuals, 229 (52.3\%) were male and $209(47.7 \%)$ were female. The age of all subjects were obtained with a span of 21 to 83 years with a mean spread of age was $40.79 \pm 14.77$ years. The characteristics of the studied subjects depicted in Table 1.
Table 1 showed that large numbers of patients $(214,48.8 \%)$ between $20-40$ years. $175(40.0 \%)$ patients aged $40-60$ years while the 60-80 year age group included $45(10.3 \%)$ patients. Some $(4,0.9 \%)$ normal individuals were above and equal to 80 year. The body mass index of most of the individuals $(281,64.2 \%)$ was normal. $142(32.4 \%)$ individuals diagnosed as overweight. Few $(11,2.5 \%)$ had obesity whereas only four $(0.9 \%)$ were underweight. Hypertension was reported in more individuals $(79.0 \%)$ when measured by using a standard validated sphygmomanometer as compared to automated instrument $(76.0 \%)$.

Table 2 showed the features and characteristic of the selected population comprised of 229 males and 209 females. Average age of individual's was $40.79 \pm 14.77$ years within range of 21-83 years. Range of body mass index was from 17.58 to 31.45 kilogram/ meter $^{2}$ with an average of $23.97 \pm 2.98 \mathrm{kilogram} /$ meter $^{2}$ whereas the mean weight and height also reported in table. The mean difference between recordings of automated oscillometric and manual systolic and diastolic BPs were $5.16 \pm 4.40 \mathrm{mmHg}$ and $5.57 \pm 3.30 \mathrm{mmHg}$ respectively. The ranges for differences in automated and manual systolic and diastolic BPs found to be $-8-+19$ and $-8-+16 \mathrm{mmHg}$ respectively.

Table 3 highlights the measurement of BP of normal individuals between manual and automated instruments. Average (Mean \pm SD) SBP $(130.78 \pm 17.31)$ and DBP $(86.96 \pm 10.26 \mathrm{mmHg})$ measured by automated instrument found to be significantly greater as compared to SBP

\section{Table 1: Distribution of age, body mass index and hypertension}

\begin{tabular}{|c|c|c|c|}
\hline Parameter & Variables & Frequency $\mathrm{N}=438$ & Percentage (\%) \\
\hline \multirow[t]{4}{*}{ Age } & $20-40$ year & 214 & 48.8 \\
\hline & 40-60 year & 175 & 40.0 \\
\hline & $60-80$ year & 45 & 10.3 \\
\hline & $\geq 80$ year & 4 & 0.9 \\
\hline \multirow[t]{3}{*}{ Body Mass Index $\left(\mathrm{kg} / \mathrm{m}^{2}\right)$} & <18.5 (Underweight) & 4 & 0.9 \\
\hline & 18.5-24.9 (Normal Weight) & 281 & 64.2 \\
\hline & 25-29.9 (Over Weight) & 142 & 32.4 \\
\hline \multirow[t]{2}{*}{ Hypertension } & Present (Sphygmomanometer) & 346 & 79.0 \\
\hline & Present (Automated) & 333 & 76.0 \\
\hline
\end{tabular}

\begin{tabular}{lcc} 
Table 2: Subject's characteristics & \\
\hline Characteristics (N = 438) & Mean or frequency & Standard deviation \\
\hline Age (Year) & 40.79 & 14.77 \\
Sex (Male/Female) & $229 / 209$ & - \\
Weight (Kilogram) & 60.42 & 7.87 \\
Height (Centimeter) & 158.81 & 6.59 \\
Body Mass Index (Kilogram/Meter $\left.{ }^{2}\right)$ & 23.97 & 2.98 \\
Difference between two apparatuses (mmHg) & & $137.16-185.82$ \\
$\quad$ Systolic Blood Pressure & 5.16 & $17.58-31.45$ \\
$\quad$ Diastolic Blood Pressure & 5.57 & -8.40 \\
\hline
\end{tabular}




\begin{tabular}{|c|c|c|c|c|c|}
\hline \multirow[t]{2}{*}{ Parameter and apparatus } & \multirow{2}{*}{$\begin{array}{c}\text { Scatter for blood Pressure } \\
\text { Mean } \pm \text { SD }\end{array}$} & \multicolumn{2}{|c|}{$95 \% \mathrm{Cl}$ of the mean } & \multirow[t]{2}{*}{ Z-statistic } & \multirow[t]{2}{*}{ p-value (LOS) } \\
\hline & & LB & UB & & \\
\hline \multicolumn{6}{|l|}{$\mathrm{SBP}(\mathrm{mmHg})$} \\
\hline Sphygmomanometer & $126.32 \pm 13.47$ & 125.05 & 127.58 & 18.40 & $p=0.000^{\#}$ \\
\hline Automated & $130.78 \pm 17.31$ & 129.15 & 132.40 & & \\
\hline Mean Difference & $4.46 \mathrm{mmHg}$ & & & & \\
\hline \multicolumn{6}{|l|}{$\mathrm{DBP}(\mathrm{mmHg})$} \\
\hline Sphygmomanometer & $81.70 \pm 8.63$ & 80.89 & 82.51 & 29.16 & $p=0.000^{\#}$ \\
\hline Automated & $86.96 \pm 10.26$ & 85.99 & 87.92 & & \\
\hline Mean Difference & $5.26 \mathrm{mmHg}$ & & & & \\
\hline
\end{tabular}

$(126.32 \pm 13.47)$ and DBP $(81.70 \pm 8.63 \mathrm{mmHg})$ measured by manual sphygmomanometer.

However, the mean differences of $4.46 \mathrm{mmHg}$ in SBP and of $5.26 \mathrm{mmHg}$ in DBP were statistically significant $(\mathrm{p}=0.000)$. The statistical agreement of $95.0 \%$ confidence limits for SBP and DBP noted using digital instrument (129.15 to $132.40 \mathrm{mmHg}$ and 85.99 to $87.92 \mathrm{mmHg}$ ) was significantly raised than manual instrument (125.05 to $127.58 \mathrm{mmHg}$ and 80.89 to $82.51 \mathrm{mmHg}$ ).

Bland-Altman difference plot (Figures, 1 and 2) showed the limits of agreement between two devices of measuring BP which displays a scatter diagram of the differences plotted against the averages of the two measurements. However, horizontal lines are drawn at the mean difference and at the limits of agreement of the differences.

Amount of bias between mean systolic and diastolic blood pressures noted on automated and manual sphygmomanometer apparatuses were 4.46 (-5.48 to $14.42 \mathrm{mmHg}$ ) and 5.25 (-2.14 to $12.65 \mathrm{mmHg}$ ).

Difference between digital and manual readings for both pressures found to elevate subsequently the average BP was also rose which known as the error of electronic measurement is shown in next table four. Plots in Figures, 1 and 2 reported that there was a significant agreement between automated oscillometric and manual devices. Nevertheless, the Bland-Altman plots indicated a positive linear trend for both, SBP and DBP readings between automated and manual measurements.

Table 4 shows the variations in the differences in BP measurement among normal healthy individuals between automated and manual instruments. Subjects explored for three categories of BP based on manual reading $(<120 \mathrm{mmHg}, 120-140 \mathrm{mmHg}$ and $>140 \mathrm{mmHg}$ ) in order to observe the trend of differences. It was found to be dependent on increment in BP. An increase in SBP and DBP readings between digital and manual measurements was significantly $(\mathrm{p}=0.000)$ accompanied with an increment

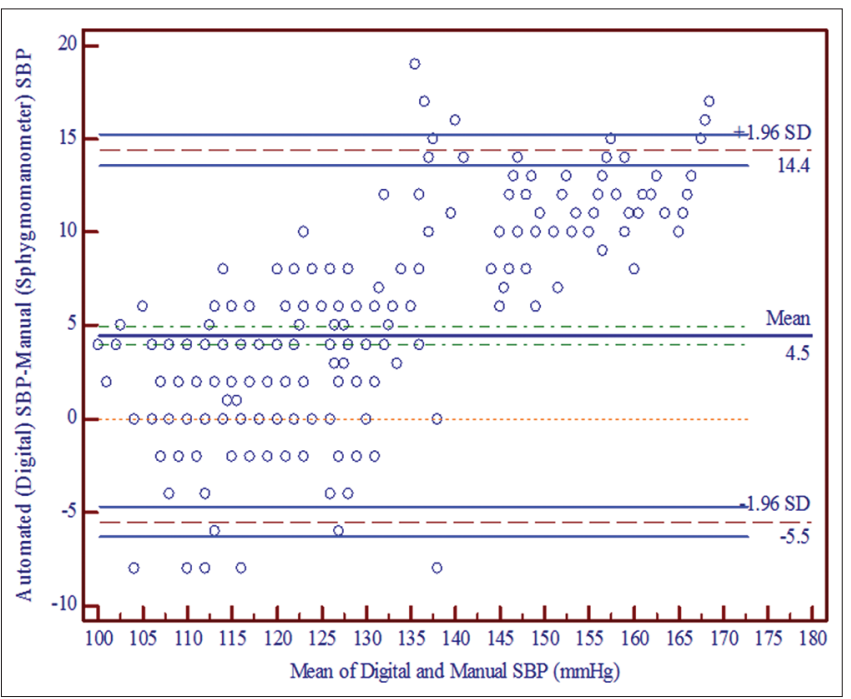

Figure 1: Bland-Altman plot showing the reading difference and limits of agreement ofSBP between automated and manual apparatuses

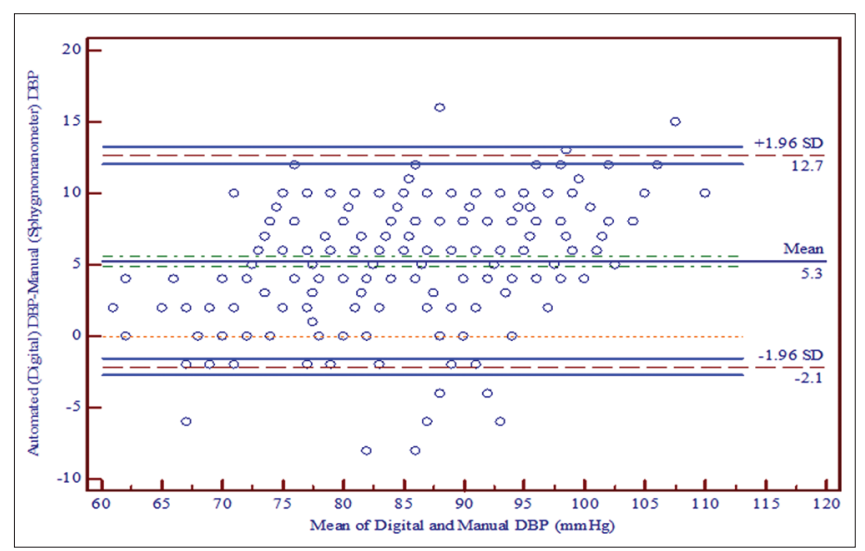

Figure 2: Bland-Altman plot showing the reading difference and limits of agreement of DBP between automated and manual apparatuses

in their difference recordings with respect to these categorizations. However, the differences found to be more in SBP than DBP within three categories.

An average of differences of SBP measured between automated and manual instruments was significantly $(p=0.000)$ elevated among those who had a manual systolic 


\begin{tabular}{|c|c|c|c|c|c|}
\hline \multirow[t]{2}{*}{ Parameter and Variable } & \multirow{2}{*}{$\begin{array}{c}\text { Difference of Blood Pressure } \\
\text { Mean } \pm S D\end{array}$} & \multicolumn{2}{|c|}{$95 \% \mathrm{Cl}$ of the Mean } & \multirow[t]{2}{*}{ F-statistic } & \multirow[t]{2}{*}{ p-value (LOS) } \\
\hline & & LB & UB & & \\
\hline \multicolumn{6}{|l|}{$\mathrm{SBP}(\mathrm{mmHg})$} \\
\hline$<120 \mathrm{mmHg}$ & $1.34 \pm 3.21$ & 0.75 & 1.93 & 199.33 & $\mathrm{p}=0.000^{\#}$ \\
\hline $120-140 \mathrm{mmHg}$ & $3.40 \pm 4.13$ & 2.87 & 3.94 & & \\
\hline$>140 \mathrm{mmHg}$ & $11.05 \pm 2.93$ & 10.45 & 11.66 & & \\
\hline \multicolumn{6}{|l|}{$\mathrm{DBP}(\mathrm{mmHg})$} \\
\hline$<120 \mathrm{mmHg}$ & $3.85 \pm 3.59$ & 3.19 & 4.51 & 26.48 & $p=0.000^{\#}$ \\
\hline $120-140 \mathrm{mmHg}$ & $5.09 \pm 3.61$ & 4.62 & 5.56 & & \\
\hline$>140 \mathrm{mmHg}$ & $7.45 \pm 3.45$ & 6.73 & 8.16 & & \\
\hline
\end{tabular}

\#The mean differences are highly/strongly significant at the o.ooo levels of significance. [CI-Confidence Interval; UB-Upper Bound; LB-Lower Bound; LOS-Level of Significance]

\begin{tabular}{|c|c|c|c|c|}
\hline \multirow[t]{2}{*}{ Characteristic } & \multirow[t]{2}{*}{ Variable } & \multicolumn{2}{|c|}{ Hypertension (Automated) } & \multirow[t]{2}{*}{ Total } \\
\hline & & Absent & Present & \\
\hline \multirow[t]{7}{*}{ Hypertension (Manual) } & Absent & 332 & 14 & 346 \\
\hline & & $75.8 \%$ & $3.2 \%$ & $79.0 \%$ \\
\hline & Present & 1 & 91 & 92 \\
\hline & & $0.2 \%$ & $20.8 \%$ & $21.0 \%$ \\
\hline & Total & 333 & 105 & 438 \\
\hline & & $76.0 \%$ & $24.0 \%$ & $100.0 \%$ \\
\hline & Value of $\mathrm{K}$ & $\mathrm{P}=0.000^{\#}$ & & \\
\hline
\end{tabular}

\#Limits of agreement are highly/strongly significant at the 0.000 levels of significance

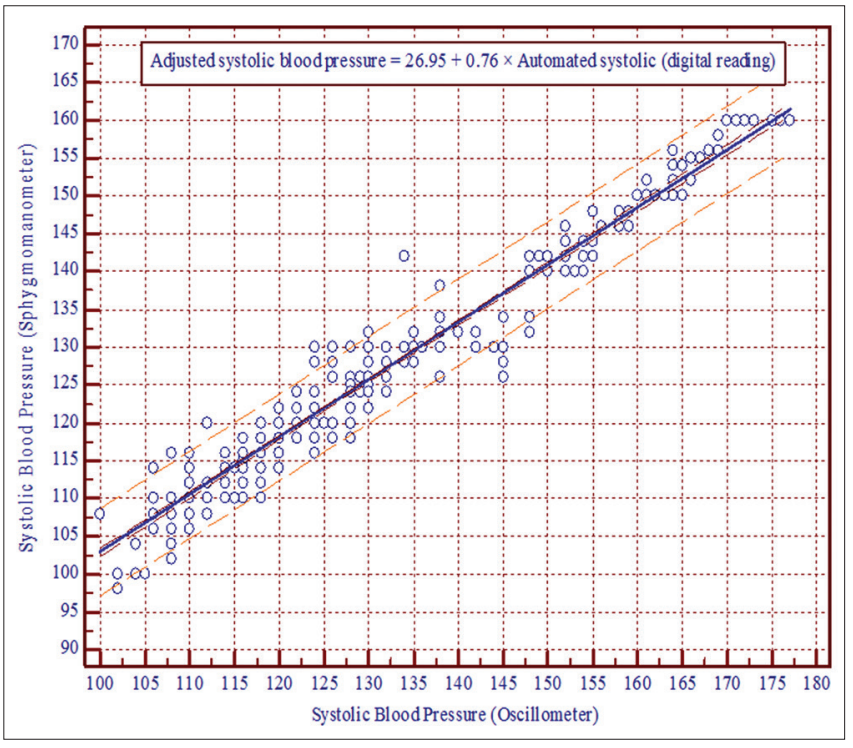

Figure 3: Regression analysis shows the prediction of manual SBP using automated SBP

reading of above $140 \mathrm{mmHg}(11.05 \pm 2.93 \mathrm{mmHg})$ as compared to those who had readings between $120 \mathrm{mmHg}$ and $140 \mathrm{mmHg}(3.40 \pm 4.13 \mathrm{mmHg})$ and below $120 \mathrm{mmHg}$ $(1.34 \pm 3.21 \mathrm{mmHg})$.

Average differences of DBP measured between automated and manual instruments was significantly $(\mathrm{p}=0.000)$ elevated among those who had a manual systolic reading of above $140 \mathrm{mmHg}(7.45 \pm 3.45 \mathrm{mmHg})$ as compared

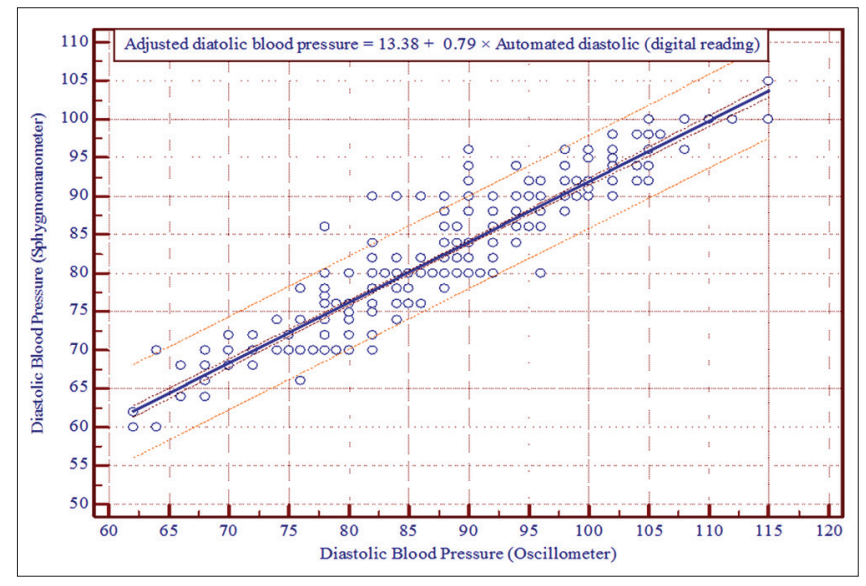

Figure 4: Regression analysis shows the prediction of manual DBP using automated DBP

to those who had readings between $120 \mathrm{mmHg}$ and $140 \mathrm{mmHg}(5.09 \pm 3.61 \mathrm{mmHg})$ and below $120 \mathrm{mmHg}$ (3.85 $\pm 3.59 \mathrm{mmHg})$.

Cohen's kappa statistic used to measure the agreement between two apparatuses in order to compare the detection rate of hypertension among population which can be sees in Table 5. However, a BP recordings of normal healthy individuals of $<140 / 90 \mathrm{mmHg}$ reported as absence of hypertension as per WHO diagnosis criteria to detect hypertension whereas recordings of $>140 / 90 \mathrm{mmHg}$ used as presence of hypertension. 
Table 5 demonstrates that the automated apparatus found with significant agreement of reporting approximately similar degree of measurement of $\mathrm{BP}$ in detecting hypertension when compared to sphygmomanometer among normal healthy individuals. Measurement of agreement using Cohen's Kappa found to be high (0.90). However, statistically highly significant $(p=0.000)$ mutual agreement of more than $95 \%$ confidencewas judged between the rate of detection of hypertension by two apparatuses.

Relationship between manual and automated BP readings had reported using regression analysis when automated BPreadings considered as the independent variable.

The coefficient of determination for $\operatorname{SBP}\left(\mathrm{R}^{2}=0.95\right)$ was very high when manual readings of $\mathrm{BP}$ compared to automated apparatus. In Figure 3, linear regression analysis showed showed that the automated SBP is the significant predictor $(\beta=0.76, \mathrm{p}=0.000)$ of SBP noted manually with a regression equation [Adjusted SBP $=26.95$ $+0.76 \times$ automated SBP (digital)].

The coefficient of determination for DBP $\left(\mathrm{R}^{2}=0.87\right)$ was high when manual BP readings compared to automated apparatus (digital). Figure 4 shows that DBP noted on automated was also the significant predictor $(\beta=0.79$, $\mathrm{p}=0.000)$ of DBP measured manually with a regression equation [Adjusted DBP $=13.38+0.79 \times$ Automated DBP (digital)].

Discussion: Scientific research studies conducted during the last decades have clearly showed that automated oscillometric device do not require skilled expertise for BP measurement and they can be used as a primary tool for early diagnosis and management of high BP. In the similar context, the present study had evaluated the role of automated BP measuring devices in early health care for the management of high BP among normal population.

Mercury sphygmomanometers have been considered as a gold standard for measuring blood pressure reading for a long time. However, in the recent past oscillometric equipment had gain importance. ${ }^{20}$ Present study demonstrated the difference between digital and manual readings. Both SBP and DBP pressures found to increase and subsequently the average $\mathrm{BP}$ was also elevated which is known as the error of electronic measurement but there was a significant agreement between automated and manual devicesas shown by table four.

However, results of the present study indicated a positive linear trend for both, SBP and DBP readings between automated and manual measurements which is in agreement with the results of a study carried out by
Mansoor et al in 2016 observed that there was a positive linear trend for SBP reading as the average SBP is raising, the difference between manual and electronic readings (subsequently called the error of electronic measurement) is also rising. ${ }^{17}$

Present study demonstrated that the mean difference in SBP was $5.16 \mathrm{mmHg}$ and $5.57 \mathrm{mmHg}$ for DBP between automated and manual apparatuses were statistically significant which is in agreement with the recent study conducted by Sujanitha in 2018, observed that the mean difference of the mercury and oscillometric readings in SBP is $4.18 \mathrm{mmHg}$ in right arm and $3.66 \mathrm{mmHg}$ in left arm which are statistically significant. ${ }^{21}$

Myers MG et al reported that there is a higher level of discrepancy when using these devices on hypertensive patients. ${ }^{16}$ Results of the present study revealed that automated apparatus found with significant agreement of reporting approximately similar degree of measurement of $\mathrm{BP}$ in detecting hypertension when compared to manual. Further, study explored for three categories of $\mathrm{BP}$ based on manual reading and was found to be dependent on increment in BP which is correlated with the results of the study conducted by Mansoor et al showed that the differences between manual and electronic readings for the two groups were statistically significant. ${ }^{17}$

Estimates of the cut-point for normal BP for routine manual versus automated values are still preliminary but Beckett, and Godwin suggested that conventional office $\mathrm{BP}$ at $140 / 90 \mathrm{~mm} \mathrm{Hg}$ is equivalent to an automated reading of 135/85 $\mathrm{mm} \mathrm{Hg}$ taken in the office with subjects resting alone in a quiet room. ${ }^{22}$ In the present study, 346/79.0\% and $333 / 76.0 \%$ individuals reported hypertensive using manual and automated techniques respectively according to a cut-point of $<140 / 90 \mathrm{~mm} \mathrm{Hg}$ for normal manual BP. However, research carried out by Ma Y et al showed that variation in BP readings by two instruments within participant/technician accounts for most of the variation. ${ }^{23}$

The performance of mercury and digital models was similar and significantly better than aneroid models. However, digital devices requiring no expertise at all showed better accuracy as compared to mercury sphygmomanometer. ${ }^{14}$

Automated apparatus found with significant agreement of reporting approximately similar degree of measurement of $\mathrm{BP}$ in detecting hypertension when compared to sphygmomanometer among normal healthy individuals. Measurement of agreement found to be high was in agreement with the study showed that the agreement of measurement between aneroid and gold standard (mercury 
instrument) and between digital and gold standard (mercury instrument) was analyzed using kappa coefficient were 0.88 and 0.39 for the aneroid and digital devices respectively and both were statistically significant. ${ }^{15}$

Study demonstrated that the hypertension detected in more $(79.0 \%)$ individuals using a sphygmomanometer as compared to automated (76.0\%) instrument which is correlated with the findings suggested by Shahbabu et al (2016), showed that the aneroid device has diagnosed more (86.7\%)hypertensive as compared to digital device $(80.0 \%)$.

However in a study Nelson et al observed that automated or digital BP monitors are easy to use. Once the patient and cuff are positioned properly, the operator needs only to press a button on the unit to begin measuring $\mathrm{BP}$ with the oscillometric technique. No stethoscope is needed and BP and pulse readings are displayed on the unit's screen and this was noted that automated wrist and arm manometers are being used in health care settings and by many individuals in their homes. ${ }^{24}$

Nevertheless, the SBP reading found with small average difference of $5.16 \mathrm{mmHg}$ whereas $5.57 \mathrm{mmHg}$ was noted for DBP between automated and manual apparatuses and thus both the apparatuses can be used interchangeably but while caution particularly in diagnosing hypertension with using an automated blood pressure recording device. Study alarmed that the automated devices should be used with care, and their standardization should be done from time to time.

\section{Implications}

Study highlights that the BP reading noted on automated device is comparable with the recordings of mercury devices, and are useful in detection and management of high blood pressure. Its operation is simple and do not require expertise of auscultation. However, the readings of automated devices may be slightly on higher side. Present study evaluated that automated oscillometric BP measuring devices may be considered as aprimary tool to detect high BP without medical skill.

\section{CONCLUSION}

Present study evaluated that automated oscillometric BP measuring devices are simple to operate, free from environmental toxicity. Readings of these devices are comparable to mercury devices but readings of SBP are slightly higher as compared to mercury devices. They may be considered as a primary tool to detect high BP without medical help and consequently helpful in early diagnosis of diseases. Moreover,automated apparatus found to be statistically similar in detecting hypertension when compared to sphygmomanometer.

\section{REFERENCES}

1. Deshpande S, Patel N, Godbole V, Champaneri V, Singh N and Patel R. Awareness and Approach towards Hypertension Management among General Practitioners of Western Vadodara. J Clin Diagn Res 2014; 8(8): MC05-MC08.

2. Lim SS, Vos T, Flaxman AD, Danaei G, Shibuya K, AdairRohani $\mathrm{H}$, et al. A comparative risk assessment of burden of disease and injury attributable to 67 risk factors and risk factor clusters in 21 regions, 1990-2010: a systematic analysis for the Global Burden of Disease Study 2010. Lancet 2012; 380:2224-2260.

3. Gupta R. Trends in hypertension epidemiology in India. J Hum Hypertens 2004; 18:73-78.

4. Reeves RA. Does this patient have hypertension? How to measure blood pressure.JAMA1995;273:1211-1216.

5. Chobanian AV, Bakris GL and Black HR. The seventh report of the Joint National Committee on the Prevention, Detection, Evaluation, and Treatment of High Blood Pressure. Hypertension 2003; 42(6)1206-1252.

6. Clark CE, Campbell JL, Evans PH and Millward A. Prevalence and clinical implications of the inter-arm blood pressure difference: a systematic review. J Hum Hypertens 2006; 20:923-931.

7. Lane D, Beevers M, Barnes N, Bourne J, John A, Malins S, et al. Inter-arm differences in blood pressure: when are they clinically significant? J Hypertens 2002; 20(6):1089-1095.

8. Sharma BK and Ramawat R. Prevalence of inter-arm blood pressure difference among clinical out patients. Int J Health Sci (Qassim) 2016; 10(2):229-237.

9. Ogedegbe $\mathrm{G}$ and Pickering T. Principles and techniques of blood pressure measurement. Cardiology Clinics 2010; 28(4):571-586.

10. Kakkad K, Damor P, Parmar B, Patel S and Dhivar N. Comparative Study of Blood Pressure Measurement by Aneroid and Digital Manual Sphygmomanometer. Natl J Community Med2016; 7(8):700-702.

11. Messelbeck $\mathrm{J}$ and Sutherland $\mathrm{L}$. Applying environmental product design to biomedical products research. Environ Health Perspect 2000;108(suppl 6):997-1002.

12. Ogedegbe $\mathrm{G}$ and Pickering T. Principles and techniques of blood pressure measurement. Cardiology Clinics 2010; 28(4):571-586.

13. O'Brien E. Has conventional sphygmomanometry ended with thebanning of mercury? Blood Press Monit 2002; 7:37-40.

14. A'Court C, Stevens R, Sanders S, Ward A, McManus R and Heneghan $C$. Type and accuracy of sphygmomanometers in primary care: a cross-sectional observational study. $\mathrm{Br}$ J Gen Pract.Internet. British Journal of General Practice; 2011;61(590):e598-e603.

15. Shahbabu B, Dasgupta A, Sarkar K and Sahoo SK. Which is More Accurate in Measuring the Blood Pressure? A Digital or an Aneroid Sphygmomanometer. J Clin Diagn Res 2016;10(3):LC11-LC14.

16. Myers MG, Mclnnis NH, Fodor GJ and Leenen FH. Comparison between an automated and manual sphygmomanometer in a population survey. Am J Hypertens 2008;21(3):280-283.

17. Mansoor K, Shahnawaz S, Rasool M, Chaudhry H, Ahuja G and Shahnawaz S. Automated Versus Manual Blood Pressure Measurement: A Randomized Crossover Trial in the Emergency Department of a Tertiary Care Hospital in Karachi, Pakistan: Are Third World Countries Ready for the Change? Open Access 
Maced J Med Sci 2016; 4(3):404-409.

18. Myers MG, McInnis NH, Fodor GJ and Leenen FHH. Comparison between and Automated and manual sphygmomanometer in a population survey. Am J Hypertens 2008; 21(3):280-283.

19. O'Brien E, Petrie J, Littler WA, de Swiet M, Padfield PL, Altman D, et al. The British Hypertension Society protocol for the evaluation of blood pressure measuring devices. J Hypertens1993; 11(Suppl 2):S43-S63.

20. Rustagi N and Singh R. Mercury and Health Care. Indian J Occup Environ Med 2010; 14:45-48.

21. Sujanitha V, Kumanan T, Guruparan M and Inthuja T. Mercury versus Oscillometric Device in Measuring Blood Pressure in
Elderly: Which Is Authentic? OALib J2018;5:e4353.

22. Beckett $L$ and Godwin $M$. The BpTRU automatic blood pressure monitor compared to 24 hour ambulatory blood pressure monitoring in the assessment of blood pressure in patients with hypertension. BMC Cardiovasc Disord 2005; 5:18.

23. Ma Y, Temprosa M, Fowler S, Prineas RJ, Montez MG, Friday JB, et al. Diabetes Prevention Program Research Group. Evaluating the accuracy of an aneroid sphygmomanometer in a clinical trial setting. Am J Hypertens 2009; 22(3):263-266.

24. Nelson D, Kennedy B, Regnerus $C$ and Schweinle A. Accuracy of automated blood pressure monitors. J Dent Hyg 2008; 82(4):35.

RW- Design of the study, data collection, reviewed the literature, manuscript preparation and critical revision of the manuscript; NS- Conceptualized study, review of literature and helped in preparing first draft and critical revision of manuscript, literature search; BKS-Concept, literature search, statistically analysed, interpreted, prepared first draft of manuscript and critical revision of the manuscript.

Orcid ID:

Dr. Ravindra Wadhvani - (D) https://orcid.org/0000-0002-5938-223X

Dr. Nazeem Siddiqui - https://orcid.org/0000-0002-1561-1985

Dr Balkishan Sharma - (D) http://orcid.org/0000-0002-3517-0101

Source of Support: Nil, Conflict of Interest: None declared.
} 